\title{
Transdermal Continuous Oxygen Therapy as an Adjunct for Treatment of Recalcitrant and Painful Wounds
}

\author{
by Danae Lowell, DPM, DABPS ${ }^{1 凶}$, Bonnie Nicklas, DPM, DABPS ${ }^{2}$, William Weily, DPM ${ }^{3}$, \\ Felicia Johnson, DPM ${ }^{4}$, Michael C. Lyons II, DPM ${ }^{5-9}$
}

The Foot and Ankle Online Journal 2 (9): 4

Oxygen has an undisputed role in wound healing. On a cellular level, oxygen impacts collagen production and development through its effects on enzymes. As such, oxygen is critically important for angiogenesis, the production of granulation tissue, as well as resistance to infection. Adequate delivery of oxygen to the wound tissue is vital for optimal healing. Historically, there have been multiple vehicles utilized to deliver oxygen in order to enhance healing. Two examples include hyperbaric oxygen and non-hyperbaric oxygen filled polyethylene or plastic bags. Both are used intermittently. Additionally, systemic delivery by nasal cannula has been utilized which can be monitored by digital pulseoximetry. Transcutaneous oxygen has been injected topically to enhance ligament healing as well as topically for surface wound healing. A new technology: Transdermal Continuous Oxygen Therapy (TCOT) is another delivery system which provides a flow of continuous pure oxygen directly to the wound bed. The authors present a series of 4 case presentations where this new technology was utilized to treat severe wounds in 4 separate patients. All wounds had been recalcitrant to multiple treatment modalities and each had a significant component of pain. The results were satisfactory in that all wounds healed completely, with the additional benefit of complete reduction in pain.

Key Words: Oxygen, pain, Transdermal Continuous Oxygen Therapy, hyperbaric, EPIFLO reproduction in any medium, provided the original work is properly cited. (CThe Foot and Ankle Online Journal (www.faoj.org)

I n 1775, Joseph Priestley a British physician made medical history with the discovery of oxygen, although, it was Lovoisier, who gave the "oxygen" to the gas discovered by Priestley. Priestley's landmark finding suggested that oxygen was necessary to sustain human life. ${ }^{1}$

Address correspondence to: Danae Lowell, DPM (W112). Louis Stokes Cleveland Department of Veterans Affairs Medical Center. 10701 East Blvd Cleveland, OH 44106. 216-791-3800 Ext 5891

\footnotetext{
${ }^{1}$ Staff Podiatrist and Assistant Residency Director. Louis Stokes Cleveland Department of Veterans Affairs Medical Center. 10701 East Blvd Cleveland, OH 44106

${ }^{2}$ Staff Podiatrist. Pittsburgh Veterans Affairs Healthcare System. University Drive C. Pittsburgh, PA 15240. 412-688-6000 ext. 606795.

37244 Sprinside Drive, Fairview, PA 16145. 814-397-2091. Submitted while a second year resident.

${ }^{4}$ Dynamic Foot Care. 554 Whitepond Drive. Suite A. Akron, Ohio 44320. 330869-0669. Submitted while a second year resident.

5 Fellow, American Health Network. 128 Pine View Drive Apt. 6. Carmel, IN 46032. 216-789-8601. Submitted while a fourth year student.
}

The origin of hyperbaric medicine is firmly rooted with the advent of underwater diving. Though the exact date is not known, amazingly there is evidence dating back as far as 4500 B.C. ${ }^{2,3}$

More recently, some notable inventors that influenced extending time underwater include DiVinci, with the first sketches of an air tight diving chamber, the Dutch inventor Drebbel who created the first true diving bell in 1620, and Halley in 1691, who discovered a way to replenish the air supply while being under water. The first recorded use of a hyperbaric chamber used for medical therapy is credited to a British physician/clergyman, Henshaw in $16622^{2,3,4}$ 
Henshaw devised a way using large bellows to either increase air pressure in the chamber to treat acute diseases or decrease pressure to treat chronic ones. The nineteenth century saw an explosion in the use of hyperbaric chambers for medical aliments of the day. From the "in Vogue" use in compression therapy spas in the 1850's to French surgeon Fountaine's development in 1879 of the first mobile hyperbaric operating room. This was reported to decrease side effects of anesthesia. ${ }^{2,3}$ The first reported use of hyperbaric chamber in North America was by a Canadian named Henshaw in 1860. Hyperbaric technology has been used extensively in military medicine over the past two centuries and is becoming more common in clinical practice. This increase in clinical medicine is due to fairly recent advancements in hyperbaric medicine and recognition and certifications by Hyperbaric Medical Society. ${ }^{5}$ Ultimately, the use of the hyperbaric oxygen chamber can be implemented in many forms, staring with the traditional model of huge and complicated walk-in chambers to the use of small plastic or metal chambers. ${ }^{6,7}$ Notwithstanding the many positive effects that oxygen can have on wound care, providing oxygen to open wounds can be very complicated and expensive, in terms of money and time.

Today, there are several methods by which oxygen is provided to patients in the clinic setting. One method employs the use of inhalation therapy to provide an enriched oxygen supply via nasal cannula, or ventral mask. Oxygen administration provided in this fashion can be used to improve tissue oxygen concentration which is vital for optimal healing and resistance to infection. Measurement of $\mathrm{PaO} 2$ can be accomplished introducing a small oxygen sensor in the tissue. Subcutaneous tissue is the first tissue to suffer from oxygen deprivation and the last to be normalized. As a result, this tissue level is the optimal place for monitoring general tissue perfusion. ${ }^{7}$ The measurement of blood saturation (pulse oximetry) is used routinely in clinical setting. This method however, primarily reflects oxygen conditions in the blood, and it only has value in situations where all factors that influence $\mathrm{PaO} 2$ are functioning optimally. ${ }^{8}$
To normalize this value to non-surgical level after major surgical procedures, the patients must be given supplementary oxygen.' Inhalation therapy is easy, cost effective, and a useful way to provide supplementary systemic oxygen which has been shown to decrease the infection rate after certain types of surgery. ${ }^{8}$

Another method of providing oxygen systemically is by way of hyperbaric technology. The use in wound healing is based on the enhanced solubility of oxygen in blood and body fluids under hyperbaric conditions. $^{10}$ In hyperbaric oxygen chambers, a patient breathing oxygen at 2 to 3 atmospheres of pressure may carry as much as 5 to $6 \mathrm{~mL}$ dissolved oxygen per $100 \mathrm{ml}$ of blood. ${ }^{11}$ This enhances oxygen delivery to hypoxic tissues. However, with most cases, the oxygen content in the blood is not the issue because blood has more than adequate supplies for wound healing as long as the tissues themselves are adequately vascularized. With systemic therapy, the oxygen is delivered via the dermal capillaries to the vicinity of the ulcer, and thereafter by diffusion through granulation tissue. With inadequate blood supply to ischemic tissue at the base of the ulcer, the benefit is questionable, although the increased flux from the distally distributed capillaries may increase concentration of the diffusionally deliver oxygen at the ulcer site. Additional work is needed to determine its full value and efficacy.

For skin ulcers, it has been reported that the superficiality of the wounds makes them particularly amenable to topical administration of hyperbaric oxygen. ${ }^{12}$ However, hyperbaric oxygen has inherent tendencies to produce vasoconstriction, toxicity, and tissue destruction. Even in topical therapy with oxygen administered at pressures as low as 1.04 atmospheres, it is necessary to tread the thin line between the beneficial effects of neovascularization and the damaging effects of toxicity with destruction of the newly formed blood vessels. ${ }^{13}$ This concern has lead some investigators toward utilization of topically applied oxygen, referred to as "topical byperbaric oxygen (THO) therapy", or even more erroneously "byperbaric oxygen therapy". 
The advocates of this topical oxygen administration claim several advantages over systemic hyperbaric oxygen, including decreased cost, increased safety, decreased complications and putative physiologic effects including decreased free radical formation and more efficient delivery of oxygen to the wound surface. $^{14}$ Specifically, oxygen is delivered directly to the skin via plastic or polyethylene bags surrounding the area of interest and secured by a constrictive device to achieve an airtight seal. Variable success has been reported, ${ }^{15-23}$ many of these results have been anecdotal. The validity of many of these reported outcomes has been examined and often refuted based on a variety of parameters. ${ }^{14}$ Additionally, others have reported that healing of diabetic foot ulcers was not accelerated by THO therapy. ${ }^{24}$ In summary, the use of topical oxygen to enhance wound healing is in and of itself nothing new, in fact published reports of topical oxygen date back to the 1960's. ${ }^{25}$

Topical application of oxygen in a focused manner, directed at the site of interest has been studied by way of transcutaneous topical injection and surface application. Specifically, transcutaneous topical injection of oxygen has demonstrated improved healing in ligaments in laboratory rats. ${ }^{26}$ Focused transdermal oxygen under a Tegaderm ${ }^{\circledR}$ patch has been applied in the research setting by Fries and others, evaluating healing in surgically placed wounds on the backs of laboratory pigs. ${ }^{27}$ The treatment was used for 3 hours daily for the first 7 days following injury. Real-time wound-bed $\mathrm{PaO} 2$ measurements were performed non-invasively. Biopsy of the wound bed by dual fluorescence staining of the tissue sections showed that the edge of oxygen treated wounds had a higher density of blood vessels than that in the edge of the room air exposed control wounds. $^{27} \quad$ In a recent study of topical oxygen, Gordillo et al., ${ }^{28}$ conducted a non-randomized enrollment of patients into Hyperbaric (HBOT, $n=32$ ) and topical oxygen (TO, $n=25$ ) treatments. Under the conditions of the study, HBOT seemed to benefit some wounds while not benefiting others. However, TO will significantly improved wound size. The authors conclude that TO treatment benefits wound healing in patients suffering from chronic wounds.
A new devise for Transdermal Continuous Oxygen Therapy (TCOT) is the EPIFLO ${ }^{\circledR}$ delivery system. This portable generator delivers 3 milliliters of pure oxygen per hour with ambient humidity, 24 hours per day, 7 days per week directly to the wound bed, through a sterile 43" long $5 \mathrm{fr}$. cannula and is covered with an occlusive dressing. Developed by Ogenix Corporation, this device weighs only a few ounces. This provides a moist wound environment which is continuously bathed in pure oxygen. At the cellular level, oxygen is metabolized, stimulating an increase in growth factors including, epithelialization, granulation tissue, glycosaminoglycan production, and collagen synthesis. A study by Said and others demonstrated its efficacy using a well-established rabbit ear model for acute wound healing. ${ }^{29}$ The resulting histological analysis of the wounds showed significantly greater healing at both day 5 and day 8 in response to oxygen therapy. ${ }^{28}$ Additionally, epithelial wound coverage was almost doubled in treated ear wounds when compared with controls. The authors concluded that epithelial wound healing was improved by the use of transdermal sustained-delivery treatment with 100\% oxygen. Most recently, three spinal cord injury patients receiving TCOT showed positive results after short term use of the EPIFLO system. ${ }^{30}$ The authors used this delivery system, for the treatment of complex lower extremity wounds in the following case reports.

\section{Case 1}

In August of 2002, a 56 year-old Caucasian male presented to the Louis Stokes VA Medical Center complaining of a non-healing painful ulcer on his right ankle since March when he injured himself with an axe while chopping wood. (Fig. 1) The patient's past medical history (PMH) was significant for CAD with an EF of $60 \%$, hyperlipidemia, hypothyroidism, HTN, PVD, history of DVT, (definitions required?) and venous insufficiency. Surgical history includes fem-fem bypass surgery in 1999. Social history includes an 85+ pack-years of smoking. Patient had been receiving no formal wound care, but performed dressing changes on his own consisting of hydrogen peroxide for cleaning and chloraseptic spray for pain relief as well as a light dry sterile cover. 


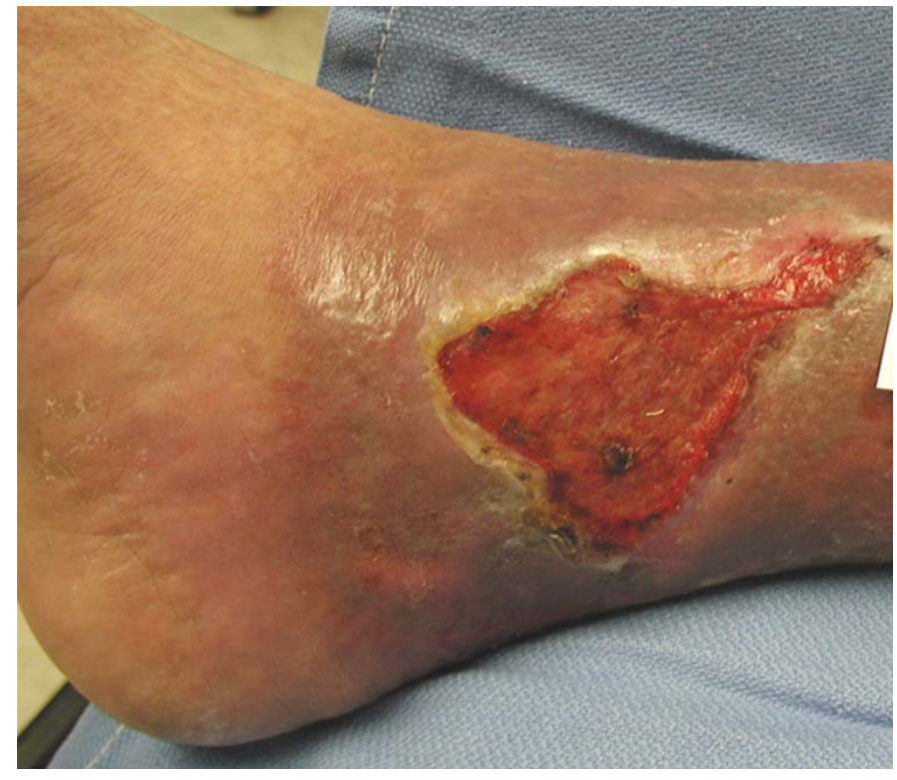

Figure 1 Case \#1, the right medial ankle at initiation of EPIFLO ${ }^{\circledR}$ therapy on November 19, 2004.

The patient had recurrent infections of the ulcer requiring multiple courses of antibiotics. Physical exam reveals palpable dorsalis pedis and posterior tibial pulses. Uniformly warm temperature noted and capillary fill intact to digits. Diffuse varicosities were noted bilaterally. The painful right ankle ulceration measured approximately $3 \times 3 \mathrm{~cm}$ with a mixed fibrogranular base and non-necrotic edges. No hyperkeratosis, tracking, probing, undermining, odor, or fluctuance noted. Multiple conventional wound care modalities were initiated including compression therapy with no resolution noted. Pain in the area remained constant. Despite meticulous wound care and appropriate consultations, the wound slowly increased in size until it $9.8 \mathrm{~cm} \times 6.5 \mathrm{~cm} \times 1 \mathrm{~cm}$ depth and was a 50/50 mix of fibrotic and granular tissue. Patient had a visual analog pain scale score of $6-$ $10 / 10$.

TCOT was initiated with the following regimen of Kaltostat ${ }^{\circledR}$ to the wound bed, hydrocolloid dressing to periphery, and EPIFLO ${ }^{\circledR}$ unit to the wound bed under occlusion with Tegaderm. Upon follow up the wound was described as less painful. Pain score on visual analog was noted to be $2 / 10$.

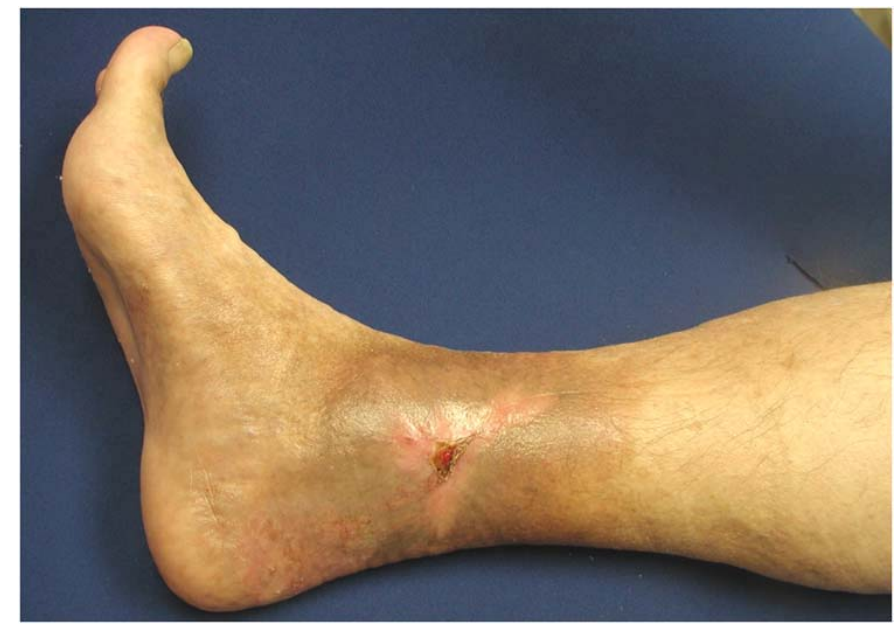

Figure 2 Case \#1, the right medial ankle at completion of EPIFLO ${ }^{\circledR}$ therapy on J une 10, 2005.

TCOT regimen consisting of weekly replacement remained in place with continued healing as evidenced by a decrease in wound size to $2.0 \mathrm{~cm} \times 1.5$ cm. (Fig. 2)

\section{Case 2}

In early August of 2004, a 64 year-old Caucasian male presented to the Louis Stokes VA Medical Center complaining of a painful ulcer on his left lateral calf which had been present off and on over the last 35 years. (Fig. 3) Most recently the ulceration had opened 2 months ago. Patient's PMH significant for history of DVT, Hepatitis C, PVD, HTN, GERD, venous insufficiency. Medications include percocet, ASA, warfarin, atenolol, metformin, mirtazapine, and glyburide. Surgical history is significant for multiple abdominal, left arm, testicle, right eye, and left leg shrapnel injuries in 1969 with notable lower extremity reconstructive procedures using skin grafts for trauma sustained from a grenade during the Vietnam conflict. Social history includes $40+$ pack-years of smoking. Wound care for the past 20 years consisted of Unna's boots and various over the counter medications and dressings. At the beginning of August patient was brought to the emergency room with an acutely infected and painful ulceration. 


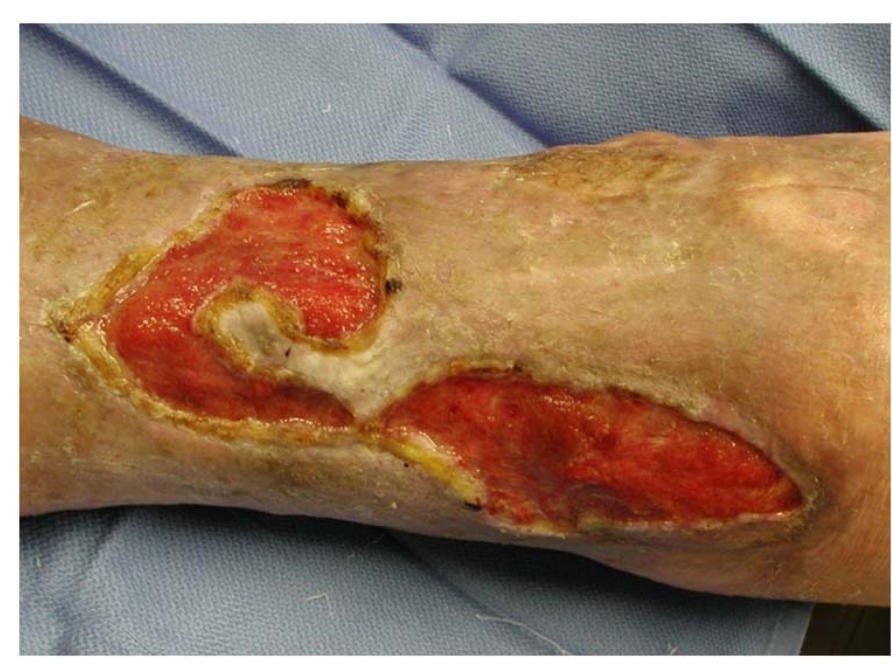

Figure 3 Case \#2, the left lateral leg at initiation of EPIFLO ${ }^{\circledR}$ therapy on November 19, 2004.

After resolution of the infection, patient continued to have a visual analog pain scale of 10/10. Physical exam reveals palpable dorsalis pedis and posterior tibial pulses. Uniformly warm temperature noted and capillary fill intact to digits. Diffuse varicosities were noted bilaterally. The painful left calf ulceration measured approximately $3 \mathrm{~cm} \times 5 \mathrm{~cm}$ x $0.5 \mathrm{~cm}$ depth with a mixed fibro-granular base and non-necrotic edges. No hyperkeratosis, tracking, probing, undermining, odor, or fluctuance was noted. There was minimal clear drainage. Conventional wound care modalities were initiated including compression therapy. Despite meticulous wound care, consults to vascular, pain management, diabetes management, infectious disease, and nutrition, the wound increased in size to $15 \mathrm{~cm} \times 8 \mathrm{~cm} \times 0.5 \mathrm{~cm}$. The wound remained excrutiatingly painful and patient was routinely prescribed narcotics for relief.

TCOT was initiated with the following regimen of hydrogel to the wound bed, restore to periphery, and EPIFLO ${ }^{\circledR}$ unit to the wound bed under occlusion with Tegaderm. Due to a reaction, all adhesives were discontinued. Patient related that the wound pain was gone within weeks of initiating EPIFLO ${ }^{\circledR}$. TCOT regimen consisting of weekly replacement remained in place over the next 5 months with continued healing as evidenced by a decrease in wound size.

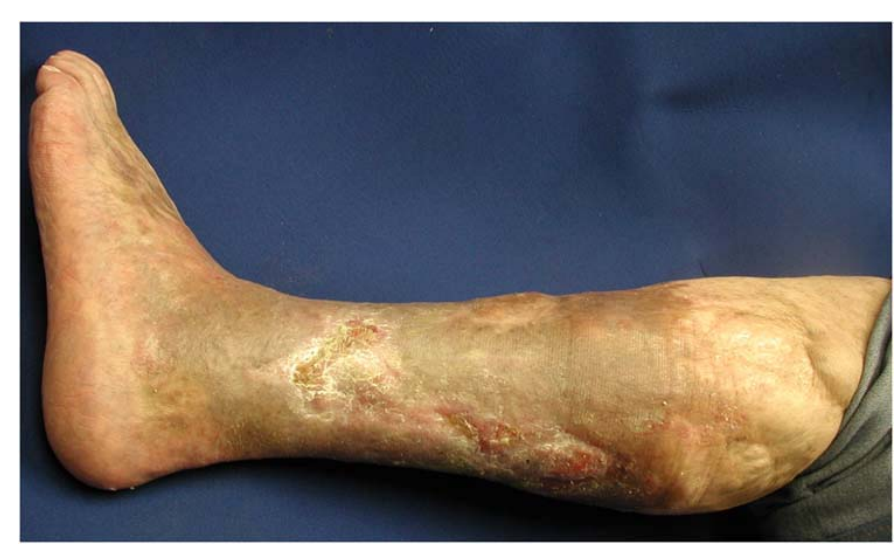

Figure 4 Case \#2, the left lateral leg after 6 months of EPIFLO ${ }^{\circledR}$ therapy. In addition to EPIFLO ${ }^{\circledR}$ therapy patient was successfully treated for underlying osteomyelitis of the fibula with 6 weeks intravenous (IV) antibiotics.

Patient eventually presented with and was diagnosed with a DVT and received treatment. Changes on plain film radiographs were concerning and confirmed by bone scan as osteomyelitis. Six weeks of intravenous (IV) antibiotics were instituted. By the end of EPIFLO ${ }^{\circledR}$ therapy the ulceration had decreased in size to $1.0 \mathrm{~cm}$ x $2.0 \mathrm{~cm}$. (Fig. 4)

\section{Case 3}

A 48 year-old male patient who developed a major wound dehiscence was the third patient treated with TCOT. Following a traumatic head injury, the patient was left an incomplete quadriplegic. He was confined to a wheelchair, and over a period of 6 years post injury the feet and ankles progressively assumed rigid adductovarus flexion contractures, resulting in adult acquired clubfoot deformities. (Fig. 5) This rendered the patient unable to wear normal shoegear, and the lateral ankles were chronically ulcerated and often infected. The patient underwent surgery to re-position and stabilize the left foot in order to make it possible to heal and then prevent chronic ulcerations of the lateral ankle, as well as allow the patient to wear normal shoegear. With no tension on the skin, the lateral incision healed uneventfully, however, the medial incision began to break down shortly after surgery. 


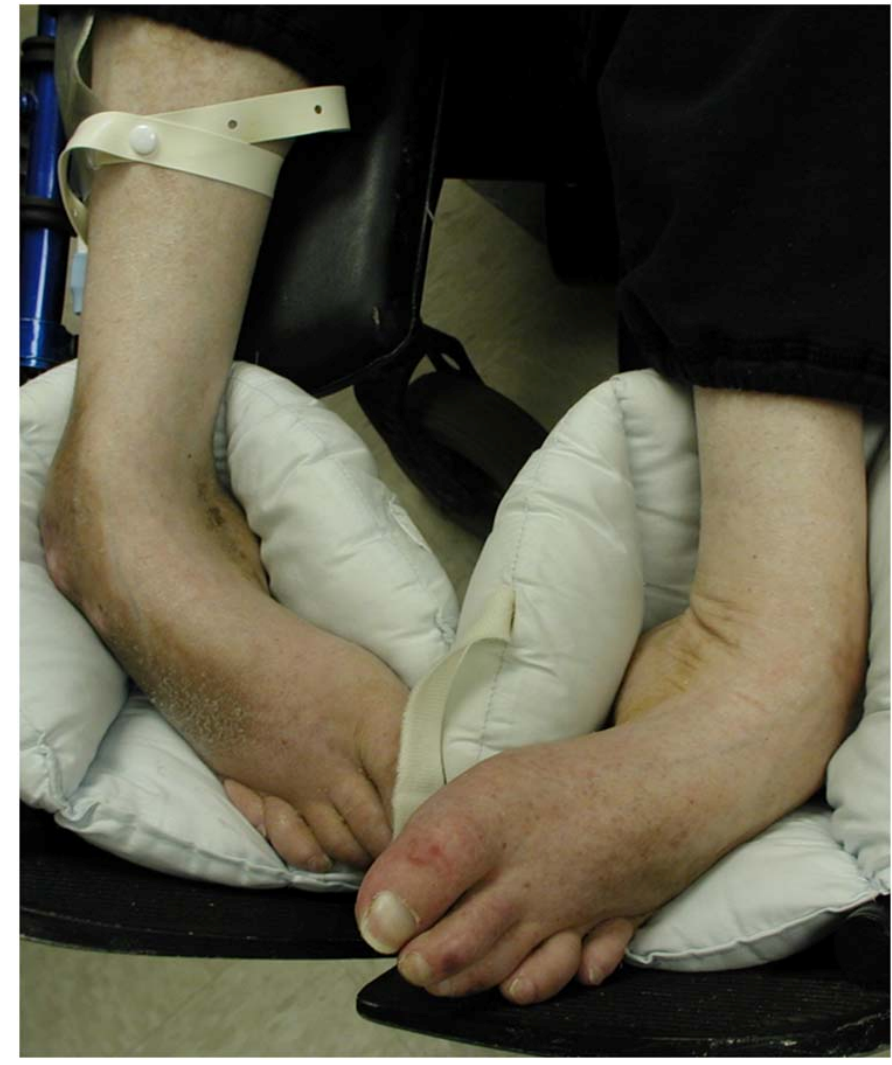

Figure 5 Case \#3, the clinical pictures of bilateral deformities prior to surgical intervention on December 2, 2004.

It was treated with a variety of wound care modalities over a short period of time as the wound changed. There was no improvement seen and it progressed to a large wound with a fibrotic base and advancing necrosis. At one point it measured $7 \mathrm{~cm}$ in length and $3 \mathrm{~cm}$ in width at its widest point. (Fig. 6) TCOT was initiated and the wound breakdown appeared to halt. Therapy was continued, in conjunction with saline wet to dry dressings and the wound successfully healed fully in 11 Weeks. (Fig. 7) Following complete healing, the right foot and ankle were operated on, which healed uneventfully. The lateral ankle ulcerations did not recur and the patient was able to wear normal shoegear. (Fig. 8)

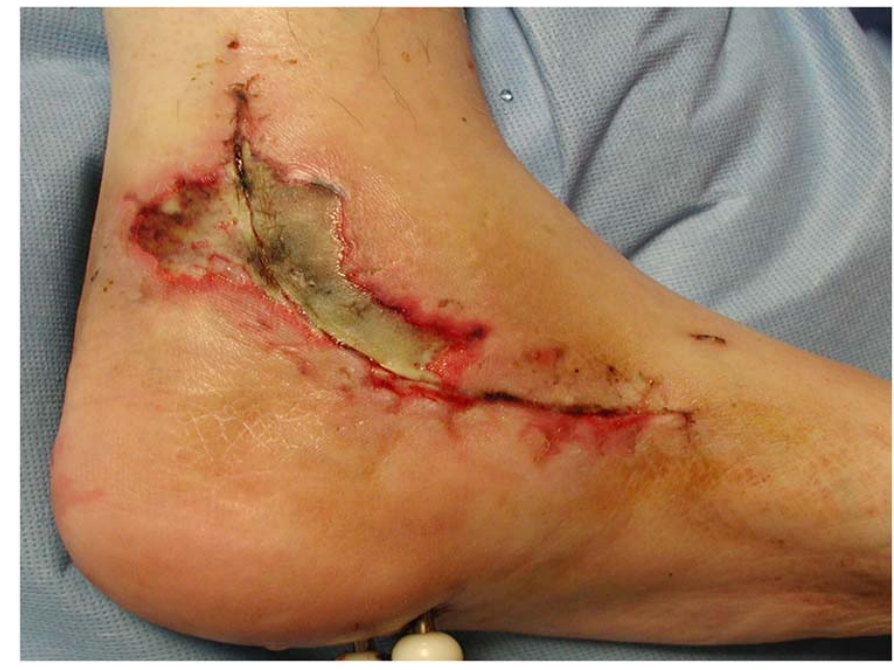

Figure 6 Case \#3, the left medial incision wound at initiation of EPIFLO ${ }^{\circledR}$ therapy on December 18, 2004.

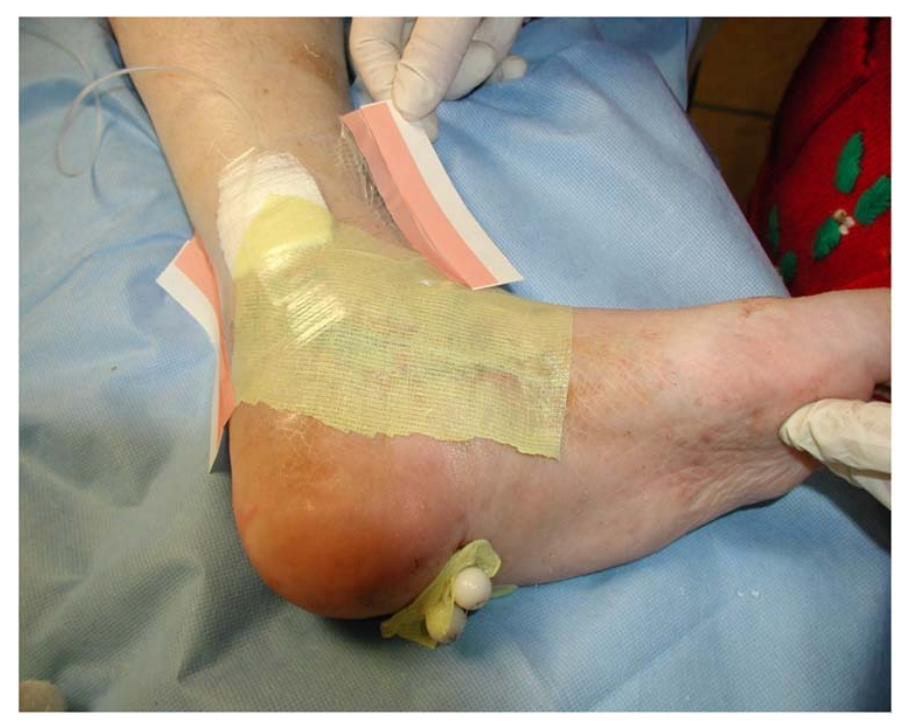

Figure 7 Case \#3, the application of EPIFLO ${ }^{\circledR}$ device under occlusive dressing for treatment of left medial incision wound.

\section{Case 4}

A 71 year-old male patient with a non-healing painful ulceration was the fourth patient treated with TCOT. By history, the patient had sustained a major crush injury and underwent a triple arthrodesis procedure in 1962. The surgery was a success, but the patient was left with an asymptomatic hypertrophic scar with overlying callus. 


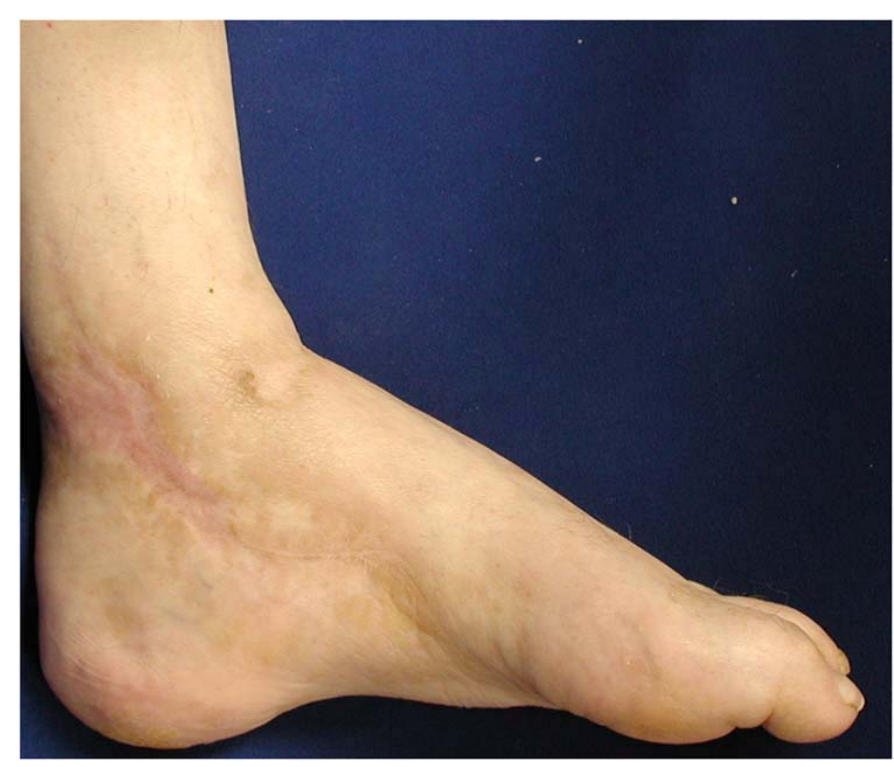

Figure 8 Case \#3, the left medial incision wound at complete healing on March 14, 2005.

For decades this was maintained with callus debridement as needed. At the time the patient presented to our clinic, his chief complaint was an ulceration which he stated had been discovered when the callus was recently debrided. (Fig. 9) The wound had been present for 4 weeks and was described as extremely painful, so severe that he was unable to bear any weight on his heel. The ulcer was located at the plantar medial aspect of the left foot, and measured $1.5 \mathrm{~cm} \times 0.5 \mathrm{~cm}$ ). The patient described the pain as a level of 10 using standard pain scale. There was some surrounding erythema and edema, and a deep necrotic core. Surgical debridement of the ulcer and scar revision was performed. The patient was treated with appropriate antibiotics. The erythema and edema resolved, but the wound healing was delayed and it remained painful at a level of 10 . Over the next few weeks the wound was treated with a variety of conventional wound care modalities, but there was little improvement in the appearance of the wound and the patient required narcotics for the pain. It progressed to a deep wound which measured $3 \mathrm{~cm}$ $\mathrm{x} 2 \mathrm{~cm} \times 2 \mathrm{~cm}$ depth.

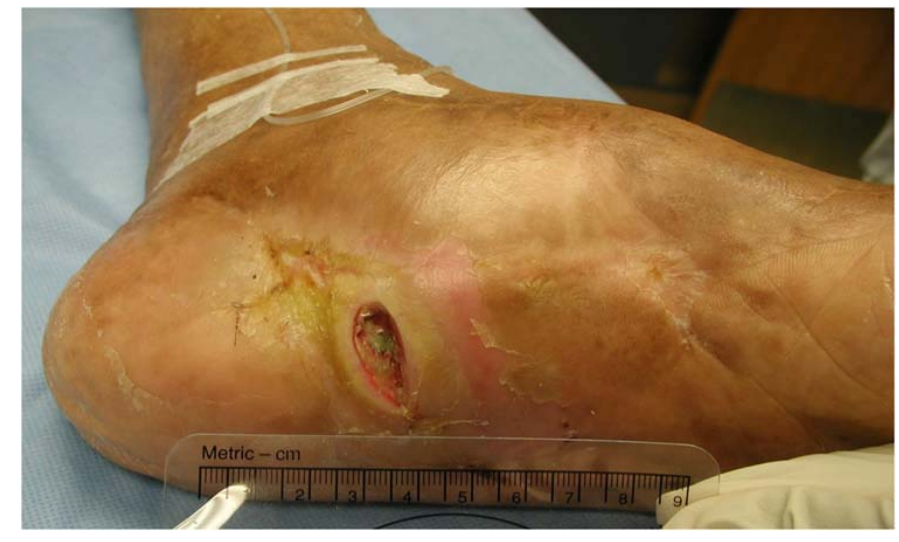

Figure 9 Case \#4, the left plantar wound at initiation of EPIFLO ${ }^{\circledR}$ therapy on J anuary 3, 2005.

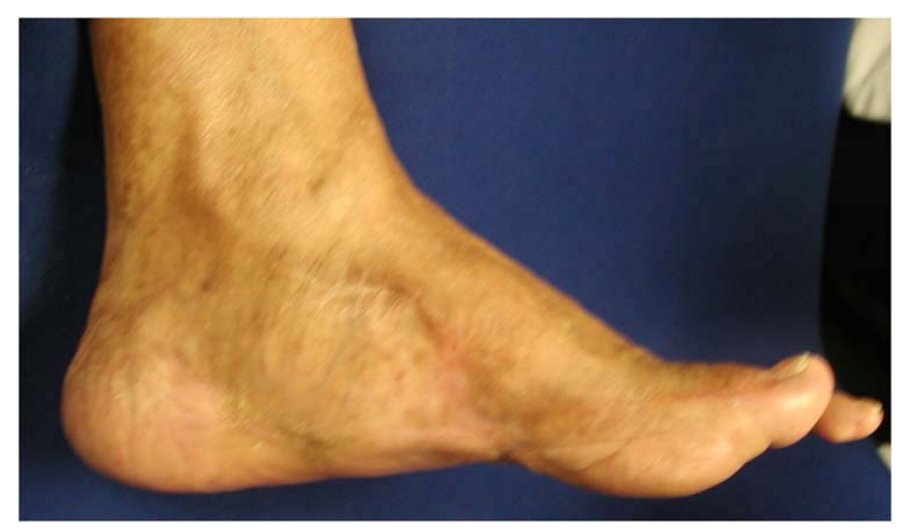

Figure 10 Case \#4, the left foot at complete healing on February 25, 2005.

TCOT with EPIFLO ${ }^{\circledR}$ device was initiated and soon after the patient related that the pain was significantly relieved. He was able to bear weight and discontinued all pain medications. The wound began to granulate and decrease in size. Therapy was continued, in conjunction with saline wet to dry dressings and the wound successfully healed fully in 8 weeks. The ulcer did not recur. (Fig. 10) 


\section{Conclusion}

Wound healing is a complex, multi-factorial biologic process that requires successful mobilization and integration of cells to repopulate the wound. This is orchestrated at least in part by a number of growth factors and is dependent in all phases of wound healing on the presence of adequate oxygen at the cellular level. Impairment of this process can be caused by the inadequacy of or lack of synchrony between critical factors. ${ }^{27}$ It is widely acknowledged that limited oxygenation of the wound site results in delayed wound healing. In fact, angiogenesis is widely considered a rate-limiting factor in wound healing. ${ }^{25}$

The authors present 4 cases of non-healing painful wounds, recalcitrant to multiple forms of therapy. In all four cases, complete healing of the wound as well as obliteration of pain was achieved with use of TCOT using EPIFLO®. This device delivers $3 \mathrm{ml}$ per hour of pure oxygen with ambient humidity directly to the wound site. The device is disposable and weighs only a few ounces and it is very patient and doctor-friendly. While success has been achieved with these four cases, further studies testing the potential of this delivery system for TCOT in preclinical and clinical settings are warranted.

\section{References}

1. Priestley J: The Discovery of Oxygen. Edinburgh the Alembic Club 1775. Presented by the University of Chicago Press, 1923

2. Spinal Rehabilitation Group: History of Hyperbaric Medicine, Melbourne Australia.

3. Neumeister M: Hyperbaric oxygen therapy. Emedicine 7, 2005. www.emedicine.com/plastic/topic526.htm accessed 08/28/2009.

4. Henshaw N: A Register for the Air, In Five chapters. Dublin, 1664.

5. Undersea Medical Society: Hyperbaric Oxygen Therapy. A Committee Report. Undersea Medical Society Publication, Inc Bethesda, MD, 1979.

6. Jacobson JH, Morsch JHC, Rendall-Baker L: Historical perspective of hyperbaric therapy. Ann NY Acad. Sci 117: 651 670, 1965.

7. Gottrup F: Measurement and evaluation of tissue perfusion in surgery. Leaper DJ, Braniicki FJ, (editors) In International Surgical Practice. Oxford University Press 15 -39, 1992.

8. Gottrup F: Oxygen in Wound Healing and Infection World J. Surg 28 (3) $312-315,2004$.

(C) The Foot and Ankle Online Journal, 2009
9. Hopf HW, Hunt TK, West JM, Blomquist P, Goodson WH 3rd, Jensen JA, Jonsson K, Paty PB, Rabkin JM, Upton RA, von Smitten K, Whitney JD: Wound tissue oxygen tension predicts the risk of wound infection in surgical Patients. Arch Surg 132: 997 - 1004, 1997.

10. Illingworth CF, Smith G, Lawson DD, Ledingham IM, Sharp GR, Griffiths JC: Surgical and physiological observations in experimental, pressure chambers. Brit J Surg 49:111 - 117, 1961.

11. Duff JH, Shibata HR, Vanschaik L, Usher R, Wigmore RA, MacLean LD: Hyperbaric oxygen: A review of treatment on eight patients. Can Med Assoc J 97: 510 - 515, 1967.

12. Heng MCY: Topical Hyperbaric Therapy for Problem Skin Wounds. Derm Surg Onco1 19: 784 - 793, 1993.

13. Heng MCY, Kloss SG: Endothelial cell toxicity in leg ulcers treated with topical hyperbaric oxygen. Am J Dermopathology 8:403 - 410, 1986.

14. Feldmeier JJ, Hopf HW, Warriner III RA, Fife CE, Gesell LB, Bennett M: UHMS position statement: topical oxygen for chronic wounds. UHM 32 (3): 157 - 168, 2005.

15. Heng MCY, Harker J, Csathy G, Marshall C, Brazier J, Sumampong, Paterno Gomez RN: Angiogenesis in necrotic ulcers treated with hyperbaric oxygen. Ostomy Wound

Management 46: 18 - 32, 2002.

16. Morgan JE: Topical therapy of pressure ulcers. Surg Gynecology Obstetrics 141:945 - 947, 1975.

17. Diamond E, et al. The effect of hyperbaric oxygen on lower extremity ulcerations. J Americ Podiatry Assoc 72:18 - 125, 1982.

18. Heng MCY: Local hyperbaric oxygen administration for leg ulcers (letter). Brit J Dermatology 109: 232 - 234, 1983.

19. Ignacio DR, Pavot AP, Azer RN, Wisotsky L: Topical oxygen therapy treatment of extensive leg and foot ulcers. J Am Podiatr Assoc 75:196 - 199, 1985.

20. Kwiecinski MG: Therapeutic value of hyperbaric oxygen in lower extremity ulcerations. J Foot Surgery 26:394 - 396, 1987.

21. Upson AV: Topical hyperbaric oxygenation in the treatment of recalcitrant open wound: a clinical report. Phys Ther 66 (9):1408 - 1412, 1986.

22. Heng MCY: Hyperbaric oxygen therapy for pyoderma gangrenosum. Aust. New Zealand J Med 14:618 - 621, 1984.

23. Kalliainen LK, Gordillo GM, Schlanger R, Sen CK:. Topical oxygen as an adjunct to wound healing: a clinical case series. Pathophys 9: $81-87,2003$.

24. Leslie CA, Sapico FL, Ginunas VJ, Adkins RH: Randomized controlled trial of topical hyperbaric oxygen for treatment of diabetic foot ulcers. Diabetes Care 1 (2), 111 - 115, 1988.

25. Fischer BH. Topical hyperbaric oxygen: treatment of pressure sores and skin ulcers. Lancet 23 (2): 405 - 409, 1969.

26. Ishii $\mathrm{H}$, Ushida $\mathrm{T}$, Tateishi $\mathrm{T}$, Miyanaga $\mathrm{Y}$ : Effects of Transcutaneous topical injection of oxygen on vascular endothelial growth factor gene into the healing ligament in rats. J Orthopedic Research 21: 1113 -1117, 2003.

27. Fries RB, Wallace WA, Roy S, Kuppusamy P, Bergdall V, Gordillo GM, Melvin WS, Sen CK:. Dermal excisional wound healing in pigs following treatment with topically applied pure oxygen. Mutation Research 579: 172 - 181, 2005. 
28. Gordillo GM, Roy S, Khanna S, Schlanger R, Khandelwal S, Phillips G, Sen CK: Topical oxygen therapy induces vascular endothelial growth factor expression and improves closure of clinically presented chronic wounds. Clinical Experimental Pharmacology Physiology 35 (8): 957 - 964, 2008.

29. Said HK, Hijjawi J, Roy N, Mogford J, Mustoe T: Transdermal sustained delivery oxygen improves epithelial healing in a rabbit ear wound model. Arch Surg 140 (10): 998 1004, 2005.

30. Banks PG, Ho C: A novel topical oxygen treatment for chronic and difficult-to-heal wounds: Case studies. J Spinal Cord Med 31(3): 297 - 301, 2008. 